\title{
The influence of cognitive-behavioral therapy on depression in dialysis patients - meta-analysis
}

Pawel Zegarow ${ }^{1}$, Malgorzata Manczak ${ }^{1}$, Jacek Rysz ${ }^{2}$, Robert Olszewski1,3

${ }^{1}$ Department of Gerontology, Public Health and Didactics, National Institute of Geriatrics, Rheumatology and Rehabilitation, Warsaw, Poland 2Department of Nephrology, Hypertension and Family Medicine, University Clinical Hospital Military Memorial Medical Academy - Central Veterans' Hospital, Lodz, Poland

${ }^{3}$ Department of Ultrasound, Institute of Fundamental Technological Research, Polish Academy of Sciences, Warsaw, Poland

Submitted: 19 September 2018

Accepted: 31 December 2018

Arch Med Sci 2020; 16 (6): 1271-1278

DOI: https://doi.org/10.5114/aoms.2019.88019

Copyright $@ 2020$ Termedia \& Banach

\section{Abstract}

Introduction: Depressive disorders are the most common mental health problem among patients undergoing dialysis. Furthermore, depression is an independent factor increasing the mortality and frequency of hospitalization in this group of patients, yet psychological intervention programs aimed at improving the mental health of dialysis patients have still not been developed. This meta-analysis aimed to assess the effects of cognitive-behavioral therapy on depressive symptoms in dialysis patients. The main hypothesis of this study is that cognitive-behavioral therapy is an effective psychological method of reducing the severity of depression symptoms among patients undergoing dialysis.

Material and methods: A systematic search was conducted using Medline, PubMed, Web of Science, Scopus and Google Scholar. Data extraction was carried out by two independent researchers. The severity of depression symptoms in the included studies was measured by the Beck Depression Inventory. A random-effects model was used to estimate the pooled mean difference of these values between patients undergoing CBT and the controls. Results: Four of the 1841 search results met the inclusion criteria with data from 226 patients who had undergone dialysis therapy due to renal disorders and psychological intervention based on cognitive-behavioral therapy. This therapy significantly reduced the level of depression symptoms in all studies included in the meta-analysis (mean difference $=-5.3, p=0.001$; $95 \% \mathrm{Cl}:-7.95$ to -2.66$)$.

Conclusions: The study showed that the use of psychological intervention based on cognitive- behavioral therapy was an effective method of decreasing the severity of depressive symptoms in hemodialyzed patients. For the sake of patient well-being, it seems reasonable to extend renal replacement therapy with psychological intervention such as cognitive-behavioral therapy.

Key words: depression, dialysis, cognitive-behavioral therapy, renal replacement.

\section{Introduction}

Currently, it is believed that chronic kidney disease is a civilization disease and one of the fastest growing chronic diseases in the United States

\author{
Corresponding author: \\ Robert Olszewski \\ Department \\ of Gerontology \\ Public Health \\ and Didactics \\ National Institute \\ of Geriatrics, \\ Rheumatology and \\ Rehabilitation \\ 1 Spartanska St \\ 02-637 Warsaw, Poland \\ Phone: +48 226709300 \\ Fax: +48 226709300 \\ E-mail: robert.olszewski@ \\ spartanska.pl
}


[1]. According to data from the World Health Organization in 2012, chronic kidney disease caused 864226 deaths worldwide, and is in the top 20 causes of death worldwide. Experts estimate that by 2030 , mortality due to chronic kidney disease will increase from 12.2 to 14 people per 100000 [2].

According to the definition of American nephrologists in 2002 (Kidney Disease Outcome Quality Initiative), chronic kidney disease is a multi-symptom syndrome resulting from permanent and irreversible damage or reduction in the number of active nephrons in the kidney parenchyma [3].

Chronic kidney disease, due to its systemic and progressive character, requires renal replacement therapy in the final stage of the disease [4]. Patients with impaired kidneys undergo renal replacement therapy, either dialysis or kidney transplant. Dialysis therapy is the most frequently used method of renal replacement therapy, but despite prolonging the lives of patients with failing kidneys, chronic use is associated with the occurrence of many side effects.

Patients treated for chronic renal failure, especially the final stages, often experience severe psychological problems such as anxiety disorders, depressive disorders, or difficulties related to coping with excessive stress [5]. Changes in the lifestyle, the need for medication, compliance with many medical recommendations on diet and daily functioning, may impair the quality of life and mental health of patients with chronic renal failure $[6,7]$. This results in non-compliance with medical prescriptions, omission of medication and thus further deterioration of health. Despite constant improvements of the treatment methods of renal failure, the proportion of patients who die from complications is still high.

Depressive disorders are the most frequent mental disorder among dialysis patients [8, 9]. Although the occurrence of depressive disorders is an independent factor increasing the mortality and frequency of hospitalization in this group of patients [10], symptoms of depression are often underestimated, and patients do not receive adequate treatment.

Therefore, the aim of this study is to thoroughly analyze published data on cognitive-behavioral therapy in dialysis patients. The main hypothesis of this study is that cognitive-behavioral therapy is an effective psychological method of reducing the severity of depression symptoms among patients undergoing dialysis.

\section{Material and methods}

The meta-analysis was prepared in accordance with the guidelines described in the article "Preferred reporting items for systematic reviews and meta-analyses: the PRISMA statement" [11].
Cognitive behavioral therapy (CBT) is one of the most researched forms of psychotherapy. This therapy was defined as therapy in which the therapist focuses on the impact that a patient's present dysfunctional thoughts has on current behavior and functioning [12].

The Beck Depression Inventory (BDI) was developed in 1961 and has been translated into many languages. This is a 21-item, self-report scale for measuring symptoms of depression. Each of 21 statements is ranked in terms of severity and scored on a 4-point scale from 0 to 3 . The total score range is 0-63 points. Higher results show greater severity of symptoms of depression [13].

\section{Search strategy}

A comprehensive search was conducted for studies on the impact of cognitive-behavioral therapy on the level of depression in hemodialyzed patients in the following databases: Medline, PubMed, Web of Science, Scopus, and Google Scholar. The databases were searched using the following key words and operators: "Cognitive behavioural therapy AND kidney", "Cognitive behavioural therapy AND renal", "CBT AND kidney", "CBT AND renal". No limit regarding the date of publication was set. Database searches ended on July 15,2018 . Only studies carried out in an adult population for renal replacement therapy and published in English were chosen.

\section{Criteria for inclusion}

In this meta-analysis, the following eligibility criteria were adopted: (1) cohort, randomized control trials or case-control study; (2) adult patients with chronic kidney disease undergoing dialysis; (3) diagnosis of depressive disorders evaluated using the Beck scale; (4) effect of cognitive behavior therapy expressed as the mean value of the Beck scale after intervention and the mean value of the Beck scale without intervention, in the control group.

\section{Extraction of data}

The databases were independently searched by two researchers who performed the initial qualification based on abstracts and titles. Studies showing data on the impact of cognitive- behavioral therapy on the functioning of renal replacement patients were selected for the next stage. Reviews of the full texts of the research were carried out by two independent researchers. Doubts were solved by the participation of a third independent researcher or during discussions about the qualitative stage of meta-analysis. The studies qualified for the next stage of meta-analysis were described in the working database with the 
following information: title of the study, year of publication, purpose, method of conducting the study, size of the research and control groups, type of intervention, results, conclusions. The endpoint of the analysis was a comparison of the level of depression measured with the Beck Depression Inventory in hemodialyzed patients after the psychological intervention (cognitive-behavioral therapy) and in the control group (without intervention).

\section{Assessment of study quality}

The quality of the included studies was assessed using the Newcastle-Ottawa Scale. The scale contains eight items in three domains concerning group selection (maximum 4 points), comparability of cases and controls (maximum 2 points) and exposure of cases and controls (maximum 3 points). Total scores range from 0 to 9.

\section{Statistical analysis}

Pooled mean difference (MD) with a 95\% confidence interval $(\mathrm{Cl})$ was estimated using a random effect model. Heterogeneity of the studies was determined by the Cochran Q test and inconsistency index $P^{2}(0-100 \%)$. The higher $R^{2}$ was, the greater was the heterogeneity. The values $25 \%, 50 \%$, and $75 \%$ indicate low, moderate, and high heterogeneity, respectively. To assess the influence of individual study meta-analysis, calculations were repeated excluding one of the studies. Publication bias was analyzed by constructing a funnel plot along with Begg-Mazumdar and Egger statistics. All statistical analyses were carried out using Statistica v.13.1 (StatSoft).

\section{Results}

As a result of the comprehensive search of the databases, 1841 articles were identified, including 3 duplicates. After initial analysis of the abstracts and titles for the full-text evaluation, 7 articles were qualified. Finally, 4 articles assessing the effectiveness of cognitive-behavioral therapy in reducing the level of depression in hemodialyzed patients were included in the meta-analysis. A summary of the studies included in the meta-analysis is presented in Table I [14-17].

In total, 4 studies were included in the metaanalysis; 226 patients were included, of whom 123 underwent psychological intervention based on the assumptions of cognitive-behavioral therapy. The population of the included studies consisted of patients with renal failure during renal replacement therapy. Subjects included in the study had received hemodialysis treatment three times a week for $3-4 \mathrm{~h}$ for at least 6 weeks before the start of the study. The study with the low- est number of people undergoing psychological intervention ( $n=11)$ was by Bahmani et al. and the study with the largest number was by Duarte et al. $(n=41)$.

The effectiveness of the psychological intervention in reducing depressive symptoms was measured using a self-report questionnaire - the Beck Depression Inventory. A statistically significant improvement after psychological effects was noted in every study included in the meta-analysis.

The degree of psychological intervention based on the assumptions of cognitive-behavioral therapy varied in duration between the individual studies. The shortest form of psychological intervention was used in the study of Lerma et al. ( 5 weeks), and the longest in the studies of Cukor et al. and Duarte et al. (3 months).

\section{Quality assessment}

Two studies (Cukor and Bahmani) were evaluated at 6 points, and two studies (Duarte and Lerma) at 7 points. None of the studies were allocated points for the assessment of outcomes as the outcomes were patient self-reports. Two studies (Cukor and Bahmani) were not allocated points for the "demonstration that the outcome of interest was not present at the start of the study" because it was not clearly detailed whether the subjects had depression at the start of the study.

\section{Meta-analysis results}

Meta-analysis calculations and forest plot for the included studies are presented in Figure 1, indicating a statistically significant difference between Beck scale values in dialysis patients who received $\mathrm{CBT}$ and controls $(\mathrm{MD}=-5.30 ; 95 \% \mathrm{Cl}$ : $-7.95--2.66 ; p<0.001)$.

Meta-analysis results with each study omitted are presented in Table II. Exclusion of individual studies from the analysis did not change the results substantially.

\section{Study heterogeneity}

There is no significant heterogeneity between studies included in the analysis: $Q=2.83 ; p=0.418$; $r^{2}=0 \%$.

Funnel plot for publication bias is presented in Figure 2. There is a slight asymmetry in the funnel plot, which displays one lower precision study with a large effect size. Despite this asymmetry, bias was not found by Begg-Mazumdar and Egger statistics: $p=0.174$ and $p=0.358$, respectively.

\section{Discussion}

To our knowledge, this is the first meta-analysis that summarizes cognitive-behavioral therapy 
Table I. Summary of studies included in the meta-analysis

\begin{tabular}{|c|c|c|c|c|c|c|c|c|c|c|c|}
\hline \multirow[t]{2}{*}{ Study } & \multirow[t]{2}{*}{ Title } & \multirow[t]{2}{*}{ Year } & \multirow{2}{*}{$\begin{array}{c}\text { Type of the } \\
\text { study }\end{array}$} & \multicolumn{5}{|c|}{ Intervention group } & \multicolumn{3}{|c|}{ Control group } \\
\hline & & & & $N$ & $\begin{array}{c}\text { Female } \\
(\%)\end{array}$ & $\begin{array}{l}\text { Age } \\
\text { (SD) }\end{array}$ & $\begin{array}{l}\text { Group vs. } \\
\text { individual }\end{array}$ & $\begin{array}{l}\text { Duration } \\
\text { of the } \\
\text { therapy }\end{array}$ & $N$ & $\begin{array}{c}\text { Female } \\
(\%)\end{array}$ & $\begin{array}{l}\text { Age } \\
\text { (SD) }\end{array}$ \\
\hline $\begin{array}{l}\text { Duarte } \\
\text { et al. }\end{array}$ & $\begin{array}{l}\text { Cognitive- } \\
\text { behavioral } \\
\text { group therapy } \\
\text { is an effective } \\
\text { treatment } \\
\text { for major } \\
\text { depression in } \\
\text { hemodialysis } \\
\text { patients [14] }\end{array}$ & 2009 & $\begin{array}{l}\text { Randomized } \\
\text { controlled } \\
\text { trial }\end{array}$ & 41 & $26(63)$ & $\begin{array}{c}52.4 \\
(15.9)\end{array}$ & $\begin{array}{l}\text { Group } \\
\text { therapy }\end{array}$ & $\begin{array}{c}12 \\
\text { weeks }\end{array}$ & 44 & $24(55)$ & $\begin{array}{l}54.0 \\
(12.7)\end{array}$ \\
\hline $\begin{array}{l}\text { Cukor } \\
\text { et al. }\end{array}$ & $\begin{array}{l}\text { Psychosocial } \\
\text { intervention } \\
\text { improves } \\
\text { depression, } \\
\text { quality of } \\
\text { life, and fluid } \\
\text { adherence in } \\
\text { hemodialysis } \\
\text { [15] }\end{array}$ & 2014 & $\begin{array}{l}\text { Randomized } \\
\text { controlled } \\
\text { trial }\end{array}$ & 33 & $27(71)$ & - & $\begin{array}{l}\text { Individual } \\
\text { therapy }\end{array}$ & $\begin{array}{c}12 \\
\text { weeks }\end{array}$ & 26 & $20(73)$ & - \\
\hline $\begin{array}{l}\text { Bahmani } \\
\text { et al. }\end{array}$ & $\begin{array}{l}\text { The effec- } \\
\text { tiveness of } \\
\text { cognitive- } \\
\text { existential } \\
\text { group therapy } \\
\text { on increasing } \\
\text { hope and } \\
\text { decreasing } \\
\text { depression in } \\
\text { women-treat- } \\
\text { ed with } \\
\text { haemodialy- } \\
\text { sis [16] }\end{array}$ & 2016 & $\begin{array}{l}\text { Randomized } \\
\text { controlled } \\
\text { trial }\end{array}$ & 11 & $11(100)$ & - & $\begin{array}{l}\text { Group } \\
\text { therapy }\end{array}$ & 6 weeks & 11 & 11 (100) & - \\
\hline $\begin{array}{l}\text { Lerma } \\
\text { et al. }\end{array}$ & $\begin{array}{c}\text { Brief } \\
\text { cognitive be- } \\
\text { havioural in- } \\
\text { tervention for } \\
\text { depression } \\
\text { and anxiety } \\
\text { symptoms } \\
\text { improves } \\
\text { quality of life } \\
\text { in chronic } \\
\text { haemodialy- } \\
\text { sis patients } \\
{[17]}\end{array}$ & 2017 & $\begin{array}{l}\text { Randomized } \\
\text { controlled } \\
\text { trial }\end{array}$ & 31 & $16(52)$ & $\begin{array}{c}41.8 \\
(14.7)\end{array}$ & $\begin{array}{l}\text { Group } \\
\text { therapy }\end{array}$ & 5 weeks & 18 & $10(56)$ & $\begin{array}{c}41.7 \\
(15.1)\end{array}$ \\
\hline
\end{tabular}

as an effective non-pharmacological method of reducing the severity of depressive symptoms in hemodialyzed patients. Our study confirmed the main hypothesis of this study. The most important result of this meta-analysis is to prove that the use of psychological intervention based on cognitive-behavioral therapy significantly reduces the level of depression among hemodialyzed patients.

It is worth noting that included studies were homogeneous, the impact of a single study on the overall result was small and there was no substantial publication bias. All these characteristics allow us to believe that meta-analysis results are reliable.

Patients on dialysis are particularly vulnerable to the occurrence of depressive disorders. The development of depression among patients undergoing dialysis is the result of overlapping disease changes occurring in the functioning of the body and the psychosocial consequences of kidney failure [18]. As is clear from the research, the start of renal replacement therapy for patients begins with severe stress, further compounded by the constant awareness of their deteriorating 


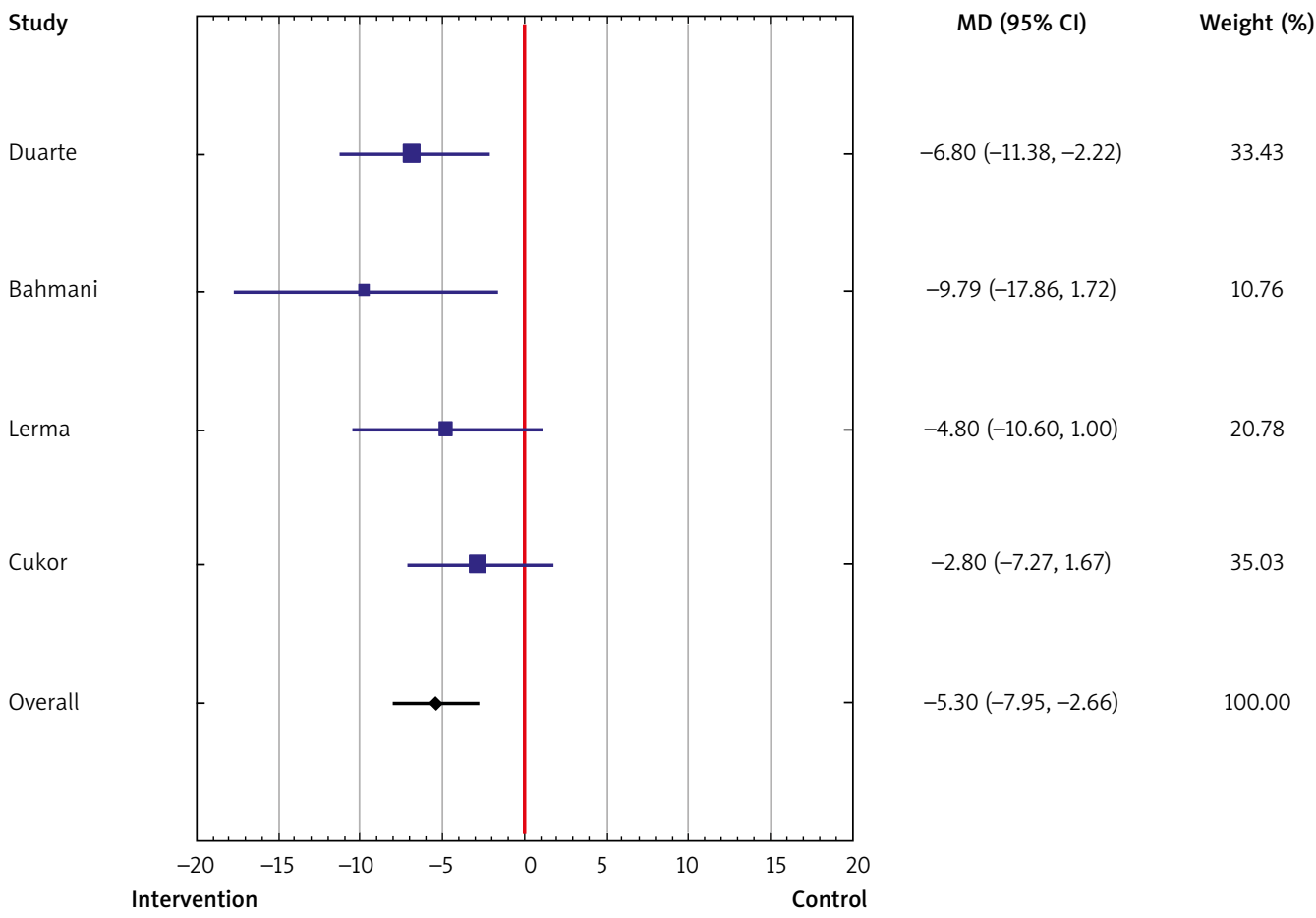

Figure 1. Difference between Beck scale values in dialysis patients who received CBT and controls

health, and the gradual loss of professional, social and family roles. The perceived level of stress has been identified as one of the factors significantly affecting the quality of life of patients undergoing dialysis $[19,20]$. In addition, the occurrence of depression is associated with a decline in the level of social support, and with a higher probability of giving up dialysis therapy [21].

In addition to psychological stressors, hemodialyzed patients experience numerous somatic symptoms as a consequence of their health and treatment process, such as insomnia [22], chronic fatigue, pruritus and muscle cramps [23]. Such significant changes connected with the disturbance of the sense of control over their own life result in a drastic reduction of the global quality of life and the occurrence of depression [24]. Researchers also draw attention to cognitive impairment in patients with chronic kidney disease, which has a negative impact on the quality of life of patients. Tamura et al. found that cognitive decline is associated with a decrease in glomerular filtration rate in patients with chronic kidney disease who are not yet on renal replacement therapy [25]. According to Tiffin-Richards et al., in 30-80\% of patients on dialysis there are various forms of cognitive dysfunction, and significantly more than in the general population of people [26, 27]. According to the estimates of the World Health Organization, depression currently affects nearly 350 million people in the world [28]. Depending on the adopted methods of measurement and diagnosis of depression, it is assumed that the problem of
Table II. Individual study influences

\begin{tabular}{|lccc|}
\hline Study & Year & $\begin{array}{c}\text { Mean difference } \\
(95 \% \mathrm{CI})\end{array}$ & $P$-value \\
\hline Duarte & 2009 & $-4.66(-8.13,-1.19)$ & 0.0084 \\
\hline Cukor & 2014 & $-6.66(-9.94,-3.37)$ & 0.0001 \\
\hline Bahmani & 2016 & $-4.76(-7.57,-1.96)$ & 0.0009 \\
\hline Lerma & 2017 & $-5.64(-9.28,-2.00)$ & 0.0024 \\
\hline
\end{tabular}

affective mood disorders occurs in nearly $25 \%$ of patients with chronic kidney disease and 30-50\% of patients on dialysis [29].

Currently it is believed that depression associated with increased mortality in dialysis patients is one of the complications of end-stage renal failure [30, 31]. According to the researchers, increased mortality among patients on dial-

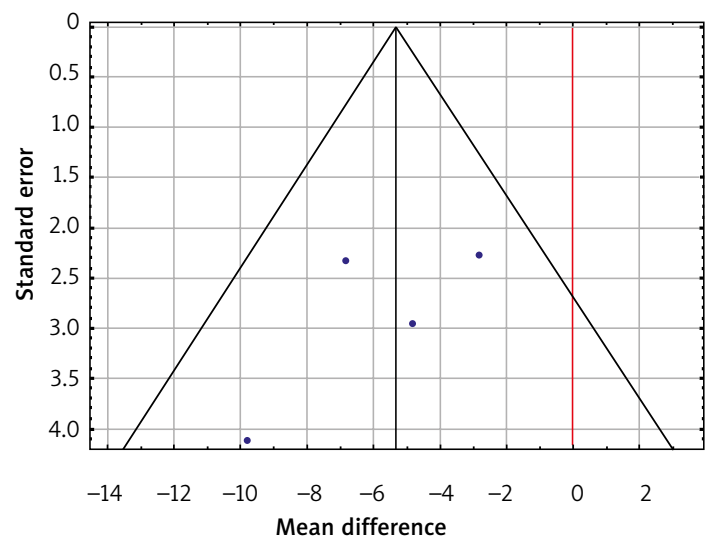

Figure 2. Publication bias 
ysis who are also depressed is associated with an increased level of proinflammatory cytokines, especially interleukin IL-6, which may accelerate disease progression and cause cardiovascular problems [32-34]. The meta-analysis conducted by Kaptage et al. showed that the inflammatory process that accompanies renal failure is one of the factors that may contribute to cardiovascular disease [35].

It is estimated that chronic kidney disease, leading in its final stage to organ failure, occurs in nearly $10 \%$ of the general population [36]. According to data from the National Institute of Health in 2009, the National Institute of Diabetes and Kidney Diseases predicts that by 2020 the percentage of people requiring renal replacement therapy will increase from $29 \%$ to $47 \%$ [37]. In 2012, 133 people per million from the general population in North Africa and 2903 people per million from the general population in Taiwan used dialysis. Considering the high prevalence of chronic kidney disease and the constantly increasing number of patients requiring renal replacement therapy, it seems reasonable to develop a program of psychological intervention aimed at improving their mental state and quality of life.

Although the occurrence of depression among hemodialyzed patients is an independent predictor of increased risk of death, cardiovascular disease risk and more frequent hospitalization, the mechanisms responsible for the association of depressive symptoms with adverse clinical results are unexplained [38]. One possible mechanism is non-compliance with medical recommendations, including skipping medication doses or self-modifying the treatment regimen. The phenomenon of non-observance of the recommendations was observed in patients undergoing hemodialysis who had depression [39].

The treatment of dialysis patients is based on complex therapeutic regimens that require frequent assessment of the effectiveness of the drugs used. The pharmacological treatment of depression in this group of patients is particularly difficult because of the increased risk of side effects due to impaired renal function and high drug load. The most common comorbidities in this group of patients are hypertension, diabetes, atrial fibrillation, coronary heart disease and infections [40, 41]; therefore, the inclusion of a new antidepressant may adversely affect the effectiveness of the entire treatment regimen. It should be emphasized that the lack of knowledge on the safe use of antidepressants among patients on dialysis is partly due to the frequent exclusion of this group of patients from clinical trials [42]. The meta-analysis carried out by Palmer et al. did not offer conclusive results on the efficacy and safety of pharmacological treatment of depression in dialysis patients, among other reasons due to poor data quality or insufficient data.

In addition, in the group of dialysis patients, the diagnosis of depression is complicated by the phenomenon of overlapping symptoms of the underlying disease and depression [43]. There are few papers in the literature on the effectiveness of pharmacological treatment of depression in dialysis patients, and their results are inconclusive. With a view to the safety of patients on dialysis who are at increased risk of cardiovascular disease, any attempt to evaluate the efficacy of antidepressants that may potentially have a cardiotoxic effect is limited. In a randomized study conducted by Friedli et al. [44], it was demonstrated that the level of depression in dialysis patients receiving the serotonin reuptake inhibitor sertraline did not differ significantly from the patients who were taking placebo at that time. The researchers emphasized that the symptoms of depressive disorders significantly decreased over 6 months, and the lack of a statistically significant difference between the groups could be explained by the strong placebo effect and the effect of participation in the study (Hawthorne effect). Similar results were obtained in the study by Hedayati et al. [45] Admittedly, the study by Kennedy et al., one of the first studies on the effectiveness of pharmacotherapy for depression in patients with renal failure, showed that 6 patients on dialysis with symptoms of severe depression after pharmacotherapy (desipramine, maprotiline) achieved a significant reduction in the severity of depression symptoms after 7 weeks of using antidepressants [46], but due to the small number of participants, the results of this study do not translate to the population of dialysis patients.

Researchers emphasize that patients with chronic illnesses require pharmacological treatment of depression; however, in the case of dialysis patients, there is a high risk of complications, with low or no benefits from this form of therapy.

Despite numerous studies on depression among patients with chronic kidney disease, there are still more questions than answers. Cukor et al. posed the following research questions: does the level of depression in patients with chronic kidney disease differ from that in the general population? Do patients with chronic kidney disease who experience depression need to be treated in a different way than patients without the disease? Does the fact of depression itself reduce renal function and would the pharmacological treatment of depression in this group of patients worsen the kidney function? [47]. It seems reasonable to plan a multi-center study that would allow con- 
struction of a psychological support program for patients undergoing renal replacement therapy. In the opinion of Cukor et al., such an intervention, focused on working with non-adaptive patterns of thinking and feelings, may become a safe and effective alternative to pharmacotherapy, which itself may be associated with higher risk in the absence of efficacy. Relationships between depression and compliance with medical recommendations, frequency of hospitalization, mortality, and quality of life, suggest that appropriate treatment of depressive disorders may play an important role in the overall treatment effect of patients with renal disorders [14].

To our knowledge, in some countries there are no governmental guidelines for the psychological care of patients treated with dialysis. Also there is no obligation to employ a psychologist in a dialysis center or a dialysis clinic. Dialysis patients as well as every insured citizen in some countries have access to free psychological care, but often they have been waiting for several months.

We think that psychological intervention aimed at reducing the severity of depressive symptoms has the potential of becoming a milestone, and setting new standards in the interdisciplinary care of renal replacement therapy patients.

This meta-analysis had 3 major limitations. First of all, only English language articles were included in the database search process. Secondly, the psychological effects described in the studies included in the meta-analysis are based on the assumptions of cognitive-behavioral therapy; however, due to the lack of a uniform pattern of conducting such interventions (duration) in each study, the patterns of interaction differed from one another. Third, the Beck Depression Inventory is a self-report screening tool that investigates the severity of depressive symptoms, but does not replace a structured interview with a psychiatrist or psychologist who could recognize depression.

In conclusion, to our knowledge, this metaanalysis is the first such work in the world. It has been shown that the use of psychological interventions based on the assumptions of cognitive-behavioral therapy is a relatively cheap, effective, nonpharmacological method in reducing the severity of depressive disorders among hemodialyzed patients. In the light of the research carried out and in the interest of the patient, it seems reasonable to extend renal replacement therapy with psychological intervention. In addition, mandatory post-training examinations should be introduced to allow early diagnosis of patients with depressive disorders and effective treatment.

\section{Conflict of interest}

The authors declare no conflict of interest.

\section{References}

1. Centers for Disease Control and Prevention (CDC. (2007). Kidney disease mortality - Michigan, 1989-2005. MMWR. Morbidity and mortality weekly report, 56(10), 225.

2. World Health Organization. Mortality and global health estimates: Causes of death. Projections for 2015-2030; Projection of death rate. Available at: http://apps.who. int/gho/data/node.main.PROJRATEWORLD?lang=en.

3. Levey AS, Eckardt KU, Tsukamoto Y, et al. Definition and classification of chronic kidney disease: a position statement from Kidney Disease: Improving Global Outcomes (KDIGO). Kidney Int 2005; 67: 2089-100.

4. Levin A, Stevens PE, Bilous RW, et al. Kidney Disease: Improving Global Outcomes (KDIGO) CKD Work Group. KDIGO 2012 clinical practice guideline for the evaluation and management of chronic kidney disease. Kidney Int Suppl 2013; 3: 1-150.

5. Cukor D, Coplan J, Brown C, et al. Depression and anxiety in urban hemodialysis patients. Clin J Am Soc Nephrol 2007; 2: 484-90.

6. Perlman RL, Finkelstein FO, Liu L, et al. Quality of life in chronic kidney disease (CKD): a cross-sectional analysis in the Renal Research Institute-CKD study. Am J Kidney Dis 2005; 45: 658-66.

7. Finkelstein FO, Finkelstein SH. Depression in chronic dialysis patients: assessment and treatment. Nephrol Dial Transplant 2000; 15: 1911-3.

8. Kimmel PL, Emont SL, Newmann JM, Danko H, Moss AH. ESRD patient quality of life: symptoms, spiritual beliefs, psychosocial factors, and ethnicity. Am J Kidney Dis 2003; 42: 713-21.

9. Palmer S, Vecchio M, Craig JC, et al. Prevalence of depression in chronic kidney disease: systematic review and meta-analysis of observational studies. Kidney Int 2013; 84: 179-91.

10. Lopes AA, Bragg J, Young E, et al. Depression as a predictor of mortality and hospitalization among hemodialysis patients in the United States and Europe. Kidney Int 2002; 62: 199-207.

11. Moher D, Liberati A, Tetzlaff J, Altman DG. Preferred reporting items for systematic reviews and meta-analyses: the PRISMA statement. Ann Int Med 2009; 151: 264-9.

12. Gaudiano BA. Cognitive-behavioral therapies: achievements and challenges. Evid Based Ment Health 2008; 11: 5-7.

13. Dols A, Chen P, Al Jurdi RK, Sajatovic M. Clinical assessment of older adults with bipolar disorder. In: Bipolar Disorder in Older Age Patients. Lehmann SW, Forester BP (eds). Springer 2017; 21-41.

14. Duarte PS, Miyazaki MC, Blay SL, Sesso R. Cognitivebehavioral group therapy is an effective treatment for major depression in hemodialysis patients. Kidney Int 2009; 76: 414-21.

15. Cukor D, Ver Halen N, Asher DR, et al. Psychosocial intervention improves depression, quality of life, and fluid adherence in hemodialysis. J Am Soc Nephrol 2014; 25: 196-206.

16. Bahmani B, Najjar MM, Sayyah M, Shafi-Abadi A, Kashani HH. The effectiveness of cognitive-existential group therapy on increasing hope and decreasing depression in women-treated with haemodialysis. Global J Health Sci 2016; 8: 219.

17. Lerma A, Perez-Grovas H, Bermudez L, Peralta-Pedrero ML, Robles-García R, Lerma C. Brief cognitive behavioural intervention for depression and anxiety symptoms improves quality of life in chronic haemodialysis patients. Psychol Psychother 2017; 90: 105-23. 
18. Bautovich A, Katz I, Smith M, Loo CK, Harvey SB. Depression and chronic kidney disease: a review for clinicians. Aust N Zeal J Psychiatry 2014; 48: 530-41.

19. Gerogianni GK, Babatsikou FP. Identification of stress in chronic haemodialysis. Health Sci J 2013; 7:

20. Cukor D, Cohen SD, Peterson RA, Kimmel PL. Psychosocial aspects of chronic disease: ESRD as a paradigmatic illness. J Am Soc Nephrol 2007; 18: 3042-55.

21. Lacson Jr E, Li NC, Guerra-Dean S, Lazarus M, Hakim R, Finkelstein FO. Depressive symptoms associate with high mortality risk and dialysis withdrawal in incident hemodialysis patients. Nephrol Dial Transpl 2012; 27: 2921-8.

22. Kerns ES, Kim ED, Meoni LA, et al. Obstructive sleep apnea increases sudden cardiac death in incident hemodialysis patients. Am J Nephrol 2018; 48: 147-56

23. King-Wing Ma T, Kam-Tao Li P. Depression in dialysis patients. Nephrology 2016; 21: 639-46.

24. Cvengros JA, Christensen AJ, Lawton WJ. Health locus of control and depression in chronic kidney disease: a dynamic perspective. J Health Psychology 2005; 10: 677-86.

25. Tamura MK, Xie D, Yaffe K, et al. Vascular risk factors and cognitive impairment in chronic kidney disease: the Chronic Renal Insufficiency Cohort (CRIC) study. Clin J Am Soc Nephrol 2011; 6: 248-56.

26. Wolcott DL, Wellisch DK, Marsh JT, Schaeffer J, Landsverk J, Nissenson AR. Relationship of dialysis modality and other factors to cognitive function in chronic dialysis patients. Am J Kidney Dis 1988; 12: 275-84.

27. Tiffin-Richards FE, Costa AS, Holschbach B, et al. The Montreal Cognitive Assessment (MoCA) - a sensitive screening instrument for detecting cognitive impairment in chronic hemodialysis patients. PLoS One 2014 9: e106700.

28. World Health Organization Fact SheetDepression A Global Public Health Concern. Retrieved from: http:// www.who.int/mediacentre/factsheets/fs369/en/ (2016).

29. Palmer S, Vecchio M, Craig JC, et al. Prevalence of depression in chronic kidney disease: systematic review and meta-analysis of observational studies. Kidney Int 2013; 84: 179-91.

30. Fan L, Sarnak MJ, Tighiouart H, et al. Depression and allcause mortality in hemodialysis patients. Am J Nephrol 2014; 40: 12-8

31. Farrokhi F, Abedi N, Beyene J, Kurdyak P, Jassal SV. Association between depression and mortality in patients receiving long-term dialysis: a systematic review and meta-analysis. Am J Kidney Dis 2014; 63: 623-35.

32. Chilcot J, Wellsted D, Da Silva-Gane M, Farrington K. Depression on dialysis. Nephron Clin Pract 2008; 108: 256-64.

33. Taraz M, Taraz S, Dashti-Khavidaki S. Association between depression and inflammatory/anti-inflammatory cytokines in chronic kidney disease and end-stage renal disease patients: a review of literature. Hemodialysis Int 2015; 19: 11-22.

34. Tsai YC, Chiu YW, Hung CC, et al. Association of symptoms of depression with progression of CKD. Am J Kidney Dis 2012; 60: 54-61.

35. Emerging Risk Factors Collaboration. C-reactive protein concentration and risk of coronary heart disease, stroke, and mortality: an individual participant meta-analysis. Lancet 2010; 375: 132-40.

36. Emerging Risk Factors Collaboration. C-reactive protein concentration and risk of coronary heart disease, stroke, and mortality: an individual participant meta-analysis. Lancet 2010; 375: 132-40.

37. Renal Data System US. USRDS 2009 Annual Data Report: Atlas of End-Stage Renal Disease in the United States. Bethesda, MD: National Institutes of Health, National Institute of Diabetes and Digestive and Kidney Diseases 2009.

38. Farrokhi F, Abedi N, Beyene J, Kurdyak P, Jassal SV. Association between depression and mortality in patients receiving long-term dialysis: a systematic review and meta-analysis. Am J Kidney Dis 2014; 63: 623-35.

39. Safdar N, Baakza H, Kumar H, Naqvi SAJ. Non-compliance to diet and fluid restrictions in haemodialysis patients. J Pak Med Assoc 1995; 45: 293-4.

40. Al-Ramahi R. Medication prescribing patterns among chronic kidney disease patients in a hospital in Malaysia. Saudi J Kidney Dis Transpl 2012; 23: 403-8.

41. Jaroszyński A, Jaroszyńska A, Dąbrowski W, et al. Factors influencing $P$ terminal force in lead V1 of the ECG in hemodialysis patients. Arch Med Sci 2018; 14: 257-64.

42. Charytan D, Kuntz RE. The exclusion of patients with chronic kidney disease from clinical trials in coronary artery disease. Kidney Int 2006; 70: 2021-30.

43. Chilcot J, Wellsted D, Farrington K. Screening for depression while patients dialyse: an evaluation. Nephrol Dial Transpl 2008; 23: 2653-9.

44. Friedli K, Guirguis A, Almond M, et al. Sertraline versus placebo in patients with major depressive disorder undergoing hemodialysis: a randomized, controlled feasibility trial. Clin J Am Soc Nephrol 2017; 12: 280-6.

45. Hedayati SS, Gregg LP, Carmody T, et al. Effect of sertraline on depressive symptoms in patients with chronic kidney disease without dialysis dependence: the CAST randomized clinical trial. JAMA 2017; 318: 1876-90.

46. Kennedy SH, Craven JL, Roin GM. Major depression in renal dialysis patients: an open trial of antidepressant therapy. J Clin Psychiatry 1989; 50: 60-3.

47. Cukor D, Kimmel PL. Treatment of depression in CKD patients with an ssri why things don't always turn out as you expect. Clin J Am Soc Nephrol 2018; 13: 943-5. 